\title{
Hepatic Myelopathy: An Unusual Neurological Complication of Advanced Hepatic Disease
}

\author{
Emiko Sobukawa, Kyoya Sakimura, Shigeru Hoshino, Moritoshi Hoshino and Kazuo Miyoshi
}

\begin{abstract}
Encephalopathy is widely known as one of the neurological complications of chronic hepatic disease. Recently, the occurrence of progressive myelopathy in patients with advanced hepatic disease has been well documented and differentiated from encephalopathy. We describe a 76-yearold man with decompensatory liver cirrhosis due to hepatitis $C$ virus infection who suffered from progressive paraplegia. Postmortem examination revealed demyelination of the lateral column of the spinal cord, especially of the thoracic segment. No evidence of spontaneous portosystemic shunts was found. These findings suggest that the patient had been affected with hepatic myelopathy, which is a rare complication of liver cirrhosis.

(Internal Medicine 33: 718-722, 1994)
\end{abstract}

Key words: liver cirrhosis, demyelination, spastic parapragia

\section{Introduction}

Hepatic encephalopathy is a common neurological complication of advanced hepatic disease. In 1949, Leigh and Card (1) first reported hepatic disease associated with myelopathy. Initially, it was suggested that encephalopathy followed the myelopathy, such as occurs in hepatoencephalo-myelopathy. However, the occurrence of hepatic myelopathy has recently been assumed to be independent of hepatic encephalopathy. We report herein a typical case of hepatic myelopathy in which the final diagnosis was made at postmortem examination.

\section{Case Report}

A 76-year-old man was admitted to our hospital because of progressive paralysis of the legs. Several weeks before admission, he had noted gait disturbance, which rapidly progressed to spastic paraplegia to the extent that he became bedridden. He had a two-year history of liver cirrhosis that had been induced by hepatitis $\mathrm{C}$ virus infection. However, he had been in fairly good condition for the previous two years, during which he had received treatment with diuretics and had shown no episode of hepatic coma.

At the age of 68 years, laryngeal cancer had been detected and treated with total laryngectomy and irradiation. After this treatment there had been no evidence of recurrence of the cancer. At that time slight liver dysfunction was initially detected. There was no history of exposure to industrial toxins, or the use of tobacco or alcohol. The family history was negative for neurological disease and liver disease.

On physical examination, he appeared cachectic and showed generalized edema. Because of the tracheotomy for total laryngectomy, he could not speak. Bilateral lungs were clear, and the heart sounds were normal. The abdomen showed marked generalized distension due to ascites. No obvious hepatomegaly, splenomegaly, or lymphadenopathy was found. On neurological examination, the patient was awake, alert, and oriented. The cranial nerve functions were intact. The muscle tonus of the lower extremities was bilaterally spastic, and their muscle strength was decreased associated with atrophy. The upper extremities were intact. No fasciculation was observed. The deep tendon reflex was hyperactive in the lower extremities, and bilateral plantar responses were extensor. The patient could not stand up or walk. No sensory abnormality was noted.

The results of laboratory examinations are presented in Table 1. The peripheral blood findings indicated normochromic microcytic anemia. Test for hepatitis B virus antigen was negative, but that for hepatitis $\mathrm{C}$ antibody was positive. A lumbar puncture yielded clear, colorless, acellular cerebrospinal fluid, for which the glucose level was $55 \mathrm{mg} / \mathrm{dl}$ (normal range, 50 to 75 ) and protein $47 \mathrm{mg} / \mathrm{dl}$ (normal range, 15 to 40 ), and microscopic examination of the fluid disclosed no fungi, acid bacilli, or other microorganisms. Anti-human T-cell lymphotrophic virus type I (HTLV-I) antibody was negative in serum and cerebrospinal fluid. Electrocardiography and chest radiography findings were normal. Cranial CT scanning performed

From the Department of Internal Medicine, Omiya Red Cross Hospital, Yono Received for publication January 31, 1994; Accepted for publication July 25, 1994

Reprint requests should be addressed to Dr. Emiko Sobukawa, the Department of Internal Medicine, Omiya Red Cross Hospital, Kamiochiai 903, Yono 
Table 1. Hematologic and Blood Chemistry Findings

\begin{tabular}{lr}
\hline White blood cells $(/ \mu \mathrm{l})$ & 6,200 \\
Red blood cells $(/ \mu \mathrm{l})$ & $2.87 \times 10^{6}$ \\
Hemoglobin $(\mathrm{g} / \mathrm{dl})$ & 9.7 \\
Hematocrit $(\%)$ & 30.1 \\
Platelet count $(/ \mu \mathrm{l})$ & $171 \times 10^{3}$ \\
Asparate amino transferase $(\mathrm{IU} / \mathrm{l})$ & $68(8-40)$ \\
Alanine aminotransferase $(\mathrm{IU} / \mathrm{l})$ & $14(5-35)$ \\
Lactic dehydrogenase $(\mathrm{IU} / \mathrm{l})$ & $788(240-470)$ \\
Cholinesterase $(\Delta \mathrm{pH})$ & $0.13(0.60-1.35)$ \\
Total bilirubin $(\mathrm{mg} / \mathrm{dl})$ & $1.1(0.3-1.1)$ \\
Prothrombin time $(\%)$ & $92(75-100)$ \\
Creatine kinase $(\mathrm{IU} / \mathrm{l})$ & $219(45-190)$ \\
Total protein $(\mathrm{g} / \mathrm{l})$ & $7.1(6.5-8.2)$ \\
Serum electrophoresis & \\
albumin $(\%)$ & $42.5(62-71)$ \\
$\alpha_{1}$-globulin $(\%)$ & $3.8(2.8-4.1)$ \\
$\alpha_{2}$-globulin $(\%)$ & $11.0(5.7-9.9)$ \\
$\beta_{\text {-globulin }(\%)}$ & $10.7(6.1-10.7)$ \\
$\gamma$-globulin $(\%)$ & $32.0(9.0-18.3)$ \\
Serum vitamin $\mathrm{B}_{12}(\mathrm{pg} / \mathrm{ml})$ & $312(230-800)$ \\
Serum folate $(\mathrm{ng} / \mathrm{ml})$ & $3.2(2.5-9.2)$ \\
\hline
\end{tabular}

before and after intravenous contrast material demonstrated normal appearance.

\section{Clinical course (Fig. 1)}

After admission, the ascites increased gradually in spite of diuretic therapy, and paralysis of the legs was progressive. The upper extremities were still intact except for muscle weakness. On the 20th hospital day, he became comatose. Blood ammonia level was $223 \mu \mathrm{g} / \mathrm{dl}$ (normal range, 4 to 50). After lactulose was administered by rectum, consciousness recovered. On the 28th hospital day, because of pneumonia due to mixed bacterial infection, Cefotiam was administered by drip infusion. $\mathrm{He}$ thereafter presented recurrent episodes of coma. Branched chain amino acids were injected by vein and lactulose was administered by rectum everyday. However, the liver cirrhosis was decompensated and the pneumonia progressed. On the 85th hospital day, the patient died of respiratory failure.

\section{Postmortem examination \\ General pathological findings}

Postmortem examination disclosed a mixed type pneumonia present in bilateral upper lobes. The liver weighed $410 \mathrm{~g}$ and displayed mesonodular cirrhosis. Microscopic examination revealed relatively thin fibrous stroma with mild lymphocytic infiltration and bile stasis. No evidence of hepatocellular carcinoma was seen. The spleen weighed $55 \mathrm{~g}$. No esophageal varices were seen. The kidneys were atrophic (lt. $80 \mathrm{~g}$, rt. $75 \mathrm{~g}$ ) with mild arterionephrosclerosis. The bone marrow showed hypoplasia with lymphoid aggregates and mucoid change of fatty marrow. Lipoid depletion of bilateral adrenal glands and testicular atrophy were present. Slight pancreatitis was disclosed, with mild dilatation of the main pancreatic duct. Microscopic examination of the heart, thyroid, parathyroid, gastrointestinal tract, and biliary tract revealed no marked abnormalities. There was no evidence of recurrent laryngeal cancer.

\section{Neuropathological findings}

Brain: The brain weighed $1,120 \mathrm{~g}$ and showed no macroscopic abnormalities. Microscopic sections showed senile plaques in the cerebral cortex, and hippocampus. The numbers of the motor neurons in the cerebrum were judged to be normal. Alzheimer type II glia were not found. There were no pathologic changes in the basal ganglia, brain stem, or cerebellum.

Spinal cord: Sections stained for myelin showed loss of myelin in the lateral columns occupied by the corticospinal tract, predominantly on the right side (Fig. 2). The loss of myelin extended from the lower cervical segments to the lumbar segments (Fig. 3). In the thoracic segments, there was a slight loss of myelin in the lateral spinothalamic and ventral spinocerebellar tracts (Fig. 2). The demyelinated area of the lateral column showed numerous lipid-laden macrophages and fibrous gliosis (Fig. 4). Axis cylinders apparently presented focal damage. Rare perivascular lymphocytic infiltration was

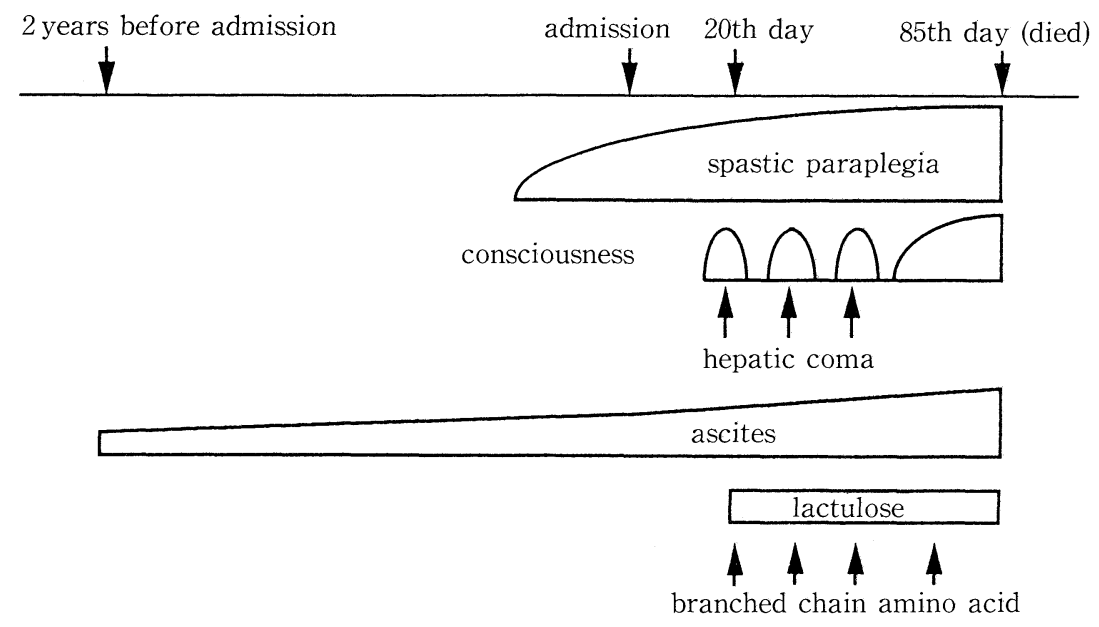

Fig. 1. Clinical course. 

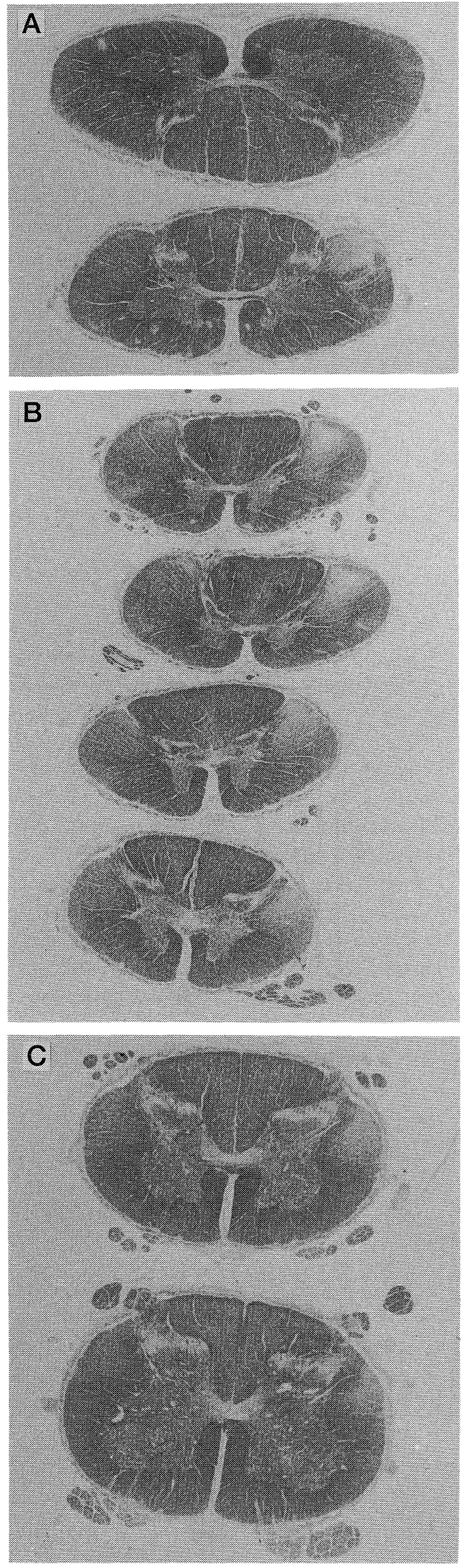

C
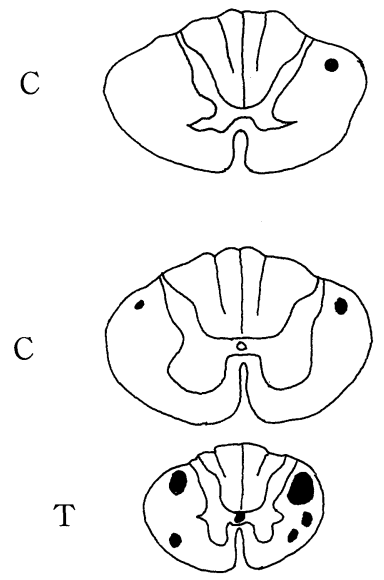

$\mathrm{T}$

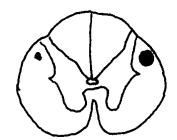

L-4

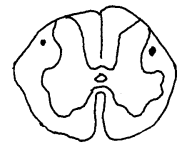

$\mathrm{S}-4$

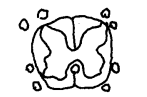

Fig. 3. The area of distribution of demyelination of the spinal cord.

present. There was no loss of myelin within the dorsal roots at any level of the spinal cord, and the gray matter was relatively intact. Histological examination of the arterial and venous spinal vessels revealed normal findings.

\section{Discussion}

Encephalopathy is a common occurrence in patients with advanced hepatic disease. The occurrence of progressive myelopathy is less widely known, but has been well documented (2). In 1949, Leigh and Card (1) first reported hepatolenticular degeneration associated with posterio-lateral column degeneration. Thereafter, Brown (3) described hepatoencephalomyelopathy which developed in a patient with hepatic coma. Subsequently, Zieve et al (4) noted shunt encephalopathy in a patient who had undergone portosystemic shunting for portal hypertension. Some cases of myelopathy occurring in patients with liver cirrhosis and spontaneous portosystemic shunt have also been reported (5-9). Initially, hepatic myelopathy was assumed to occur only after encephalopathy. However, in 1974, Fukuda and Hirayama (10) reported that hepatic myelopathy could be differentiated from hepatic encephalopathy, since the latter encephalopathy is

Fig. 2. Section of spinal cord. A: cervical segment; B: thoracic segment; $\mathrm{C}$ : lumbar segment. There is striking demyelination of the lateral cortico-spinal tract and slight loss of myelin in the lateral spinothalamic and ventral spinocerebellar tracts in the thoracic segment (myelin stain). 

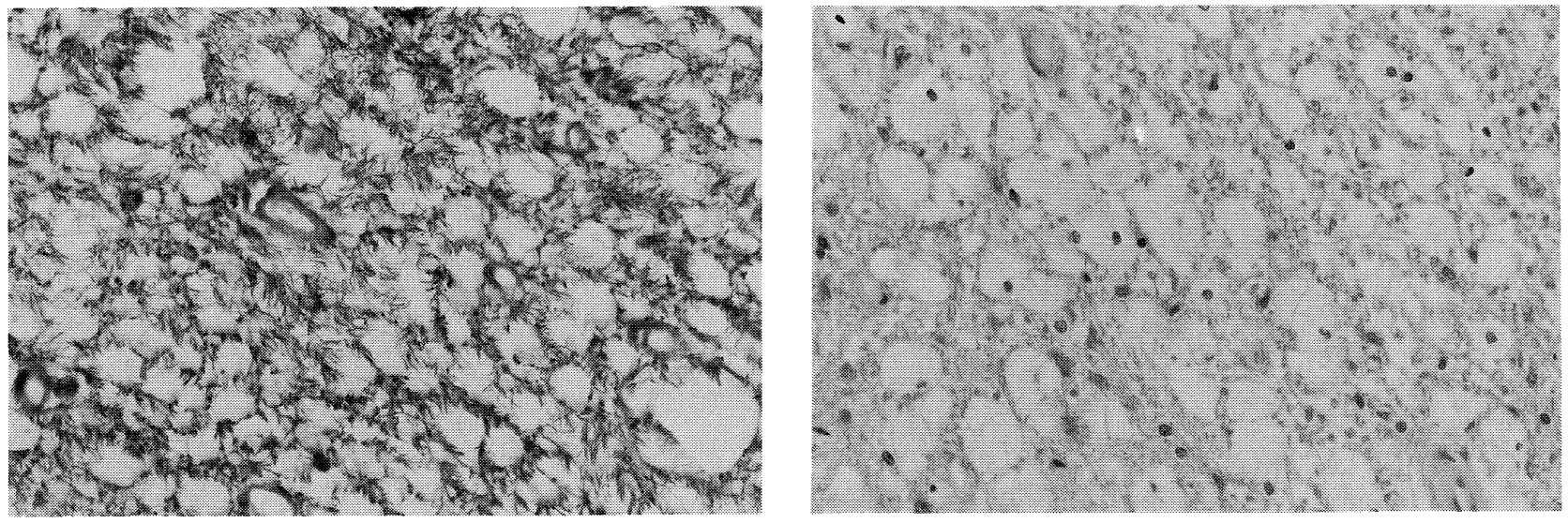

Fig. 4. The corticospinal tract in the thoracic segment. Infiltration of numerous large, lipid-laden macrophages (left) and fibrous gliosis (right) are seen (left: HE stain, right: Holzer stain, $\times 400$ ).

transient and recurrent, while the former is permanent, progressive, and intractable to medication. The common neuropathological finding in hepatic encephalopathy is the presence of Alzheimer type II glia diffusely scattered throughout the cerebral hemispheres and cerebellum while the spinal cord is intact (11). In contrast, the reported features of hepatic myelopathy were pyramidal tract lesions located predominantly in the spinal cord, especially in the thoracic cord, with no involvement of the brain stem (12).

The pathogenesis of hepatic myelopathy is not understood. However, two possible mechanisms can be postulated. First, alteration of the hepatic metabolism leads to deficiencies of essential nutrients for the central nervous system. Second, overproduction of ammonia, fatty acid, indole and mercaptan, which are abnormal metabolites of the liver reach the brain and spinal cord and cause injury to the axis cylinder, neuronal cell bodies, and myelin. Furthermore, a discrepancy exists between the tissue reaction in the corticospinal tract and sparing of other systems in the spinal cord, where axonal degeneration and demyelination, cytoplasmic astrocytosis and round cell infiltration occur, and the reaction in the brain and brain stem, where there is proliferation of Alzheimer type II glia. This discrepancy of the sensitivities indicates that there are two pathogenic mechanisms, one responsible for the lesions in the brain and brain stem and the other for those in the spinal cord. Alternatively, a single factor may be responsible for the development of both lesions, and morphologic discrepancy reflects differences in the sensitivity of the tissues in these two general areas (13).

The clinical manifestations of hepatic myelopathy are gait difficulty with insidious onset and progressive course. The upper extremities are rarely affected. Examination reveals symmetric spastic paralysis with hyperactive muscle stretch reflex of the lower extremities and extensor toe sign. Sensory findings are usually normal $(7,8,14)$, and sphincter function is almost always preserved. Most cases of hepatic myelopathy are usually preceded by episodes of encephalopathy which respond to dietary and medical management. There are no reports of effective treatment in hepatic myelopathy other than one report in which the therapy to decrease the ammonia level at the earliest stage was effective for gait disturbance (15). Therefore, it is important to observe the neurological signs and symptoms carefully and to make an early diagnosis of the spastic paraplagia in the case of chronic hepatic disease.

The spastic paraplegia which occurred following liver cirrhosis in the present patient is a typical sequence of events in hepatic myelopathy except that no preceding episodes of encephalopathy were noted. The hepatic myelopathy followed recurrent episodes of hepatic coma. As for the differential diagnoses, amyotrophic lateral sclerosis (ALS), multiple sclerosis (MS), remote effect of cancer, radiation myelopathy, HTLV-I associated myelopathy (HAM), and vascular disease of the spinal cord are enumerated. ALS is a motor neuron disease characterized by pathological degeneration of motor neurons with their eventual complete loss in the brain stem, spinal cord, and cerebral motor cortex (16). The present patient showed none of the pathological findings of ALS. The leukocyte count of cerebrospinal fluid in MS is greater than 5 cells $/ \mathrm{mm}^{3}$, and over $90 \%$ of the cells are lymphocytes. The cerebrospinal fluid total protein is less than $55 \mathrm{mg} / \mathrm{dl}$, but $\operatorname{IgG}$ is present at an abnormally high concentration and anti-myelin basic protein antibody is presented (17-19). The pathology of MS consists of demyelinated lesions of different stage of activity and maturity disseminated in various parts of the central nervous system. The lesions range from acute plaques, with active inflammatory infiltrates and macrophages laden with lipid and myelin degeneration products, to chronic and inactive demyelinated glial scars $(17,18)$. The clinical symptoms and cerebrospinal fluid and pathological findings in the present patient did not resemble those in MS. Remote effect of cancer, could not be completely denied in our patient, but the autopsy examination revealed neither recurrence of laryngeal cancer nor presence of any other malignant tumor. The resolution of paraneoplastic spinal cord syndromes with treatment of the neoplasm itself has been described (19). The features of all patients with such syndromes include sensory loss $(20,21)$, but in the present patient the 
sensorium was intact. Pathologically, in remote effect of cancer, patchy, necrotic, but relatively symmetric involvement of both the white and gray matters and blood vessel pathology may be prominent (22). The present patient had a history of radiation therapy 8 years previously. In radiation myelopathy, the cord lesion is maximal in several adjacent segments located in the center of the radiation field $(23,24)$, but in our patient only the cervical segments had been exposed to radiation while the demyelination was marked in the thoracic lesion. Pathologically, the intramedullary vascular abnormalities may be prominent in radiation myelopathy with arterial thickening, fibrosis, and antemortem thrombosis. HTLV-I infection causing adult T-cell leukemia (ATL) is often associated with myelopathy (16). However, anti-HTLV-I antibodies were negative in the serum and cerebrospinal fluid in the present patient. The pathological changes associated with vascular disease of the spinal cord are ischemic necrosis of neurons and glia, neovascularization, and fragmentation of tissue $(25,26)$, none of which were observed in our patient.

It is suggested that the features in our patient are typical of hepatic myelopathy; spastic paraplegia occurred during the course of liver cirrhosis, which is progressive and permanent. It is uncommon for hepatic myelopathy to be unaccompanied by hepatic encephalopathy, but in our patient the encephalopathy was noted after the hepatic myelopathy. Our patient showed no evidence of spontaneous portosystemic anastomosis, such as prominent esophageal varices, which is atypical of hepatic myelopathy. In the pathological study, as in typical hepatic myelopathy, myelin loss of the pyramidal tract was detected only in the spinal cord, and was particularly marked in the thoracic segments. We believe that the results of the clinical and pathological studies described above are sufficient to confirm the diagnosis of hepatic myelopathy.

Acknowledgements: We would like to thank Drs. Seiichiro Shimizu and Hideaki Kojima for their valuable assessment of the postmortem findings.

\section{References}

1) Leigh $\mathrm{AD}$, Card WI. Hepato-lenticular degeneration. A case associated with posterio-lateral column degeneration. J Neuropathol Exp Neurol 8: $338,1949$.

2) Plum F, Hindfelt B. The neurological complications of liver disease. in: Handbook of Clinical Neurology, Vinken PJ, Bruyn GW, Eds. Elsevier Science Publishers, Amsterdam, 1978, vol. 27, p. 349.

3) Brown IA. Liver-Brain Relationships. Charles C Thomas, Springfield, 1957, p. 1.
4) Zieve L, Mendelson DF, Goepfert M. Shunt encephalomyelopathy. II. Occurrence of permanent myelopathy. Ann Intern Med 53: 53, 1960.

5) Pant SS, Bhargava AN, Singh MM, et al. Myelopathy in hepatic cirrhosis. Br Med J 1: 1064, 1963.

6) Liversedge LA, Rawson MD Myelopathy in hepatic disease and portosystemic venous anastomosis. Lancet 1: 277, 1966.

7) Victor M, Adams RD, Cole M. The acquired (non-Wilsonian) type of chronic hepatocerebral degeneration. Medicine (Baltimore) 44: 345, 1965.

8) Pant SS, Rebeiz JJ, Richardson EP. Spastic paraparesis following portocaval shunts. Neurology 18: 134, 1968.

9) Shütz RM, Brunner L, Sanpradit M, et al. Myelopathie bei Leber cirrhose. Acta Hepato-Splenol 12: 361, 1965.

10) Fukuda S, Hirayama K. Hepatic myelopathy. Advances in Neurological Science 18: 563, 1974 (in Japanese, abstract in English).

11) GiangaspenoF, Dondi C, Scarani $P$, et al. Degeneration of the corticospinal tract following portosystemic shunt associated with spinal cord infarction. Virchows Arch [A] 406: 475, 1985.

12) Kincaid JC. Myelitis and myelopathy. in: Clinical Neurology, Joynt RJ, Ed. JB Lippincott Company, Philadelphia, 1992, vol. 3, chap. 48, p. 1.

13) Lefer LG, Vogel FS. Encephalomyelopathy with hepatic cirrhosis following portosystemic venous shunts. Arch Pathol 93: 91, 1972.

14) Read AE, Sherlock S, Laidlaw J, et al. The neuro-psychiatric syndromes associated with chronic liver disease and an extensive portal-systemic collateral circulation. Q J Med 36: 135, 1967.

15) Kissel P, Arnorld G, Tridon P, et al. Sur un cas de myelopathie par shunt portocave. Rev Neurol 106: 782, 1962.

16) Hudson AJ. The motor neuron diseases and related disorders. in: Clinical Neurology, Joynt RJ, Ed. JB Lippincott Company, Philadelphia 1992, vol. 4, chap. 53A, p. 1.

17) Herndon RM, Rudick RA. Multiple sclerosis and related conditions. in: Clinical Neurology, Joynt RJ, Ed. JB Lippincott Company, Philadelphia, 1992, vol. 3, chap. 33, p. 1.

18) Tourtellotte WW. The cerebrospinal fluid in multiple sclerosis. in: Handbook of Clinical Neurology, Vinken PJ, Bruyn GW, Klawans HL et al., Eds. Elsevier Science Publishers, Amsterdam, 1985, vol. 3 (47), p. 79.

19) Whitaker JN, Gupta M, Smith OF. Epitopes of immunoreactive myelin basic protein in human cerebrospinal fluid. Ann Neurol 20: 329, 1986.

20) Dorfman LJ, Forna LS. Paraneoplastic encephalomyelitis. Acta Neurol Scand 48: 556, 1971.

21) Vick N, Schulman S, Dau P. Carcinomatous cerebellar degeneration, encephalomyelitis, and sensory neuropathy (radiculitis). Neurology 19: $425,1969$.

22) Mancall EL, Rosales RK. Necrotizing myelopathy associated with visceral carcinoma. Brain 87: 639, 1964.

23) Kim YH, Faygos JV. Radiation tolerance of the cervical cord. Radiology 139: 473, 1981

24) Palmer JJ. Radiation myelopathy. Brain 95: 109, 1972.

25) Moossy J. Vascular disease of the spinal cord. in: Clinical Neurology, Joynt RJ, Ed. JB Lippincott Company, Philadelphia, 1992, vol. 3, chap. 46, p. 1.

26) Moossy J. Pathology of ischemic cerebrovascular disease. in: Neurosurgery, Wilkins RH, Rengachary SS, Eds. McGraw-Hill Book Company, New York, 1985, vol. 2, p. 1193. 